University of Nebraska - Lincoln

DigitalCommons@University of Nebraska - Lincoln

Faculty Publications from the Department of Electrical \& Computer Engineering, Department Electrical and Computer Engineering

2000

\title{
SAR Imaging Using Fully Random Bandlimited Signals
}

Dmitriy S. Garmatyuk

University of Nebraska-Lincoln

Ram M. Narayanan

University of Nebraska-Lincoln

Follow this and additional works at: https://digitalcommons.unl.edu/electricalengineeringfacpub

Part of the Electrical and Computer Engineering Commons

Garmatyuk, Dmitriy S. and Narayanan, Ram M., "SAR Imaging Using Fully Random Bandlimited Signals" (2000). Faculty Publications from the Department of Electrical and Computer Engineering. 151.

https://digitalcommons.unl.edu/electricalengineeringfacpub/151

This Article is brought to you for free and open access by the Electrical \& Computer Engineering, Department of at DigitalCommons@University of Nebraska - Lincoln. It has been accepted for inclusion in Faculty Publications from the Department of Electrical and Computer Engineering by an authorized administrator of DigitalCommons@University of Nebraska - Lincoln. 


\title{
SAR Imaging Using Fully Random Bandlimited Signals
}

\author{
Dmitriy S. Garmatyuk* and Ram M. Narayanan \\ Department of Electrical Engineering and Center for Electro-Optics \\ University of Nebraska, Lincoln, NE 68588-0511 \\ Tel.: 402-472-5141, Fax: 402-472-4732, Email: rnarayanan@unl.edu
}

\section{Introduction}

A coherent ultrawideband (UWB) random noise synthetic aperture radar (SAR) has been developed and tested at the University of Nebraska. It has been experimentally shown that this type of radar is capable of extracting the phase and the amplitude of the backscattered signal, thus enabling us to create target profiles in the frequency domain. The use of fully random waveforms (bandlimited noise) as the transmit signal is analyzed in this paper. A UWB signal model is developed and radar signal processing is simulated to yield statistical characteristics of image formation using stochastic waveforms. The influence of UWB signal characteristics on the image quality is estimated and represented graphically.

\section{UWB random signal model and simulations}

Following the series of experiments that showed a clear potential for using ultrawideband random noise synthetic aperture radar as an imaging instrument [1], we proceeded with the development of statistical characteristics of the image formation.

The simulation of UWB random noise SAR process consisted of three steps: (1) creating an UWB bandlimited noise model, (2) creating an arbitrary target function (ATF), and (3) simulating radar backscattering and signal processing (correlation receiver) to obtain the image of ATF.

To derive a signal processing model in the radar, we first have to simulate an ultrawideband signal with Gaussian-distributed amplitude and uniformly distributed phase to achieve the specified bandwidth. If we represent the stochastic ultrawideband signal $P(t)$ as $A(t) \cdot \sin \left(\omega_{0} t+\phi_{0}(t)\right)$, where $\omega_{0}$ is the central frequency and $\phi_{0}(t)$ is random phase, then, following derivations in [3], we can deduce the following expression for instantaneous frequency $\Omega$ :

$$
\Omega(t)=\sqrt{T_{1}(t)+T_{2}(t)},
$$

where

$$
T_{1}(t)=\left(\frac{d A(t)}{d t} \cdot \frac{1}{\omega_{0} \cdot A(t)}\right)^{2}, \quad T_{2}(t)=\left(1+\frac{d \phi_{0}(t)}{d t} \cdot \frac{1}{\omega_{0}}\right)^{2}
$$

In our case, the received radar signal has amplitude $A(t)=\sqrt{I^{2}+Q^{2}}$, where $I$ and $Q$ are in-phase and quadrature components of the received signal, while the random phase is a 
uniformly distributed function: $\phi_{0}(t)=\delta \omega \cdot t$, where $\delta \omega$ is a random variable. For simulation purposes, we used scaled values of frequencies and normalized values of amplitude. Having generated a vector of random amplitude and phase samples according to the signal specifications, we define the instantaneous frequency of the UWB random noise signal as:

$$
\Omega=\sqrt{\left(\frac{\nabla A(t)}{\omega_{0} \cdot A(t)}\right)^{2}+\left(1+\delta \omega \cdot \frac{2 \hat{\phi}-1}{\omega_{0}}\right)^{2}},
$$

where $\nabla A(t)$ is the gradient of amplitude samples vector, and $\hat{\phi}$ is uniformly distributed random variable in the range [0.1]. The results of modeling UWB random signal using this approach are shown in Fig. 1.
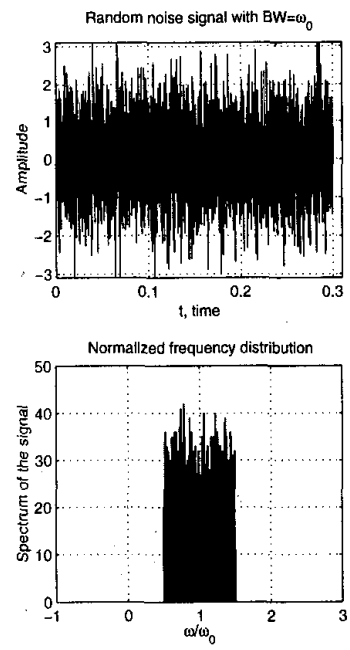
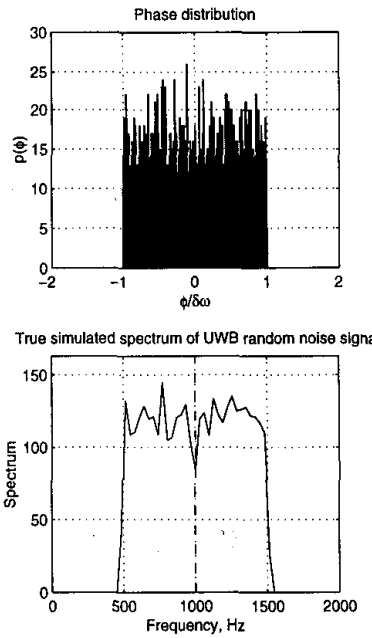

Figure 1: Modeling of UWB random signal.

Denoting this signal as $P(t)$, a generalized expression for the SAR measured echo signal is given by [2]:

$$
s(u, t)=\sum_{n} f_{n} \cdot P\left(t-\frac{2 \sqrt{x_{n}^{2}+\left(y_{n}-u\right)^{2}}}{c}\right)
$$

where $f_{n}$ is the sample of the target function at $n^{\text {th }}$ point on the target, $\mathrm{t}$ is the 'fast-time' (real time), $\mathrm{u}$ is in 'slow-time' domain (proportional to antenna movement), $(\mathrm{x}, \mathrm{y})$ are spatial coordinates.

If we define target function as

$$
f(x, y)=\sum_{n} f_{n} \delta\left(x-x_{n}, y-y_{n}\right) \Longleftrightarrow F\left(k_{x}, k_{y}\right)=\sum_{n} f_{n} e^{-j k_{x} x_{n}-j k_{y} y_{n}}=F_{t}
$$


where $F\left(k_{x}, k_{y}\right)$ is the Fourier transform of the target function $f(x, y)$, then the radar image function for the correlation receiver is given by:

$$
F_{r x}=\left(F_{t} \cdot P_{t}\right) \cdot P_{t},
$$

where $P_{t}$ is the spectrum of the transmitted signal and the bracketed expression is the spectrum of the received signal. To recover the target function, we perform spectral estimation of this signal and extract the image. Fig. 2 shows the image for both the noise-free case and noisy case ( $\mathrm{SNR}=-3 \mathrm{~dB}$ ), from which we infer that the ATF is recovered quite well.
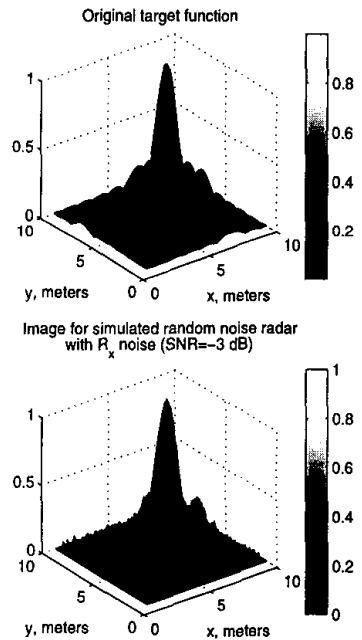
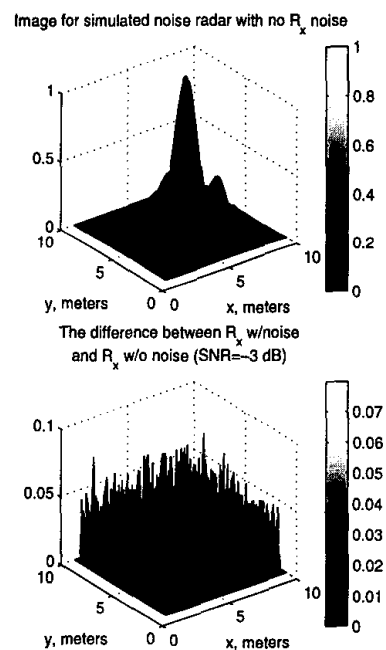

Figure 2: Modeling of target function recovery using UWB noise radar.

To perform radar processing for this simulation, the entire band of the UWB signal was divided into 128 frequency bins (since we cannot represent this signal model in the form of continuous spectrum). Obviously, the relative error between the target function recovered from noise-free backscatter and noisy backscatter will depend upon how well our signal model approximates that of the continuous UWB noise signal spectrum. The dependences of maximum and mean errors on the number of frequency bins (SNR was fixed at $-3 \mathrm{~dB}$ ) and SNR (number of frequency bins was fixed at 256) were investigated, and simulation results are shown in Fig. 3.

\section{Conclusions}

Ultrawideband random noise imaging radar performance was simulated and applied to the estimation of target function recovery. Correlation processing of backscattered and transmitted (and delayed) waveforms shows the potential for external interference and noise 
decorrelation from the radar images. Simulations clearly show that image improvement (based on relative error between simulated noise-free and noisy radar images) is directly proportional to the accuracy of continuous spectrum of UWB noise signal approximation, and to the SNR.

\section{Acknowledgements}

This work was supported by Dr. William Miceli of Office of Naval Research under Contract \#N00014-1-97-1061.

\section{References}

1. D.S. Garmatyuk and R. M. Narayanan, "SAR imaging using a coherent ultrawideband random noise radar", in Radar Processing. Technology, and Applications IV, (William J. Miceli, Editor), Proceedings of SPIE Vol. 3810, pp. 223-230, Denver, CO, July 1999.

2. M. Soumekh, "Reconnaissance with ultra wideband UHF synthetic aperture radar", in IEEE Signal Proc. Magl., Vol. 12, No. 4, pp. 21-40, July 1995.

3. L. Y. Astanin and A. A. Kostylev, Ultratideband Radar Measurements, Analysis, and Processing, The Institution of Electrical Engineers, London, 1997.
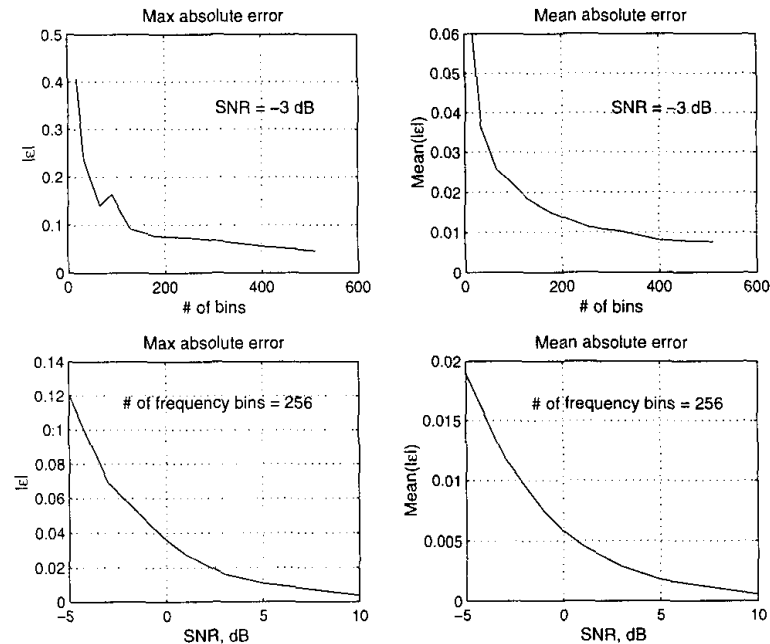

Figure 3: Error dependence upon number of frequency bins and SNR. 